\title{
Improving reservoir volumetric estimations in petroleum resource assessment using discovery process models
}

\author{
Chen Zhuoheng* and Osadetz Kirk G. \\ Geological Survey of Canada, 3033-33 $3^{\text {rd }}$ Street, NW. Calgary AB. T2L 2A7, Canada
}

\begin{abstract}
The reservoir volumetric approach represents a widely accepted, but flawed method of petroleum play resource calculation. In this paper, we propose a combination of techniques that can improve the applicability and quality of the resource estimation. These techniques include: 1) the use of the Multivariate Discovery Process model (MDP) to derive unbiased distribution parameters of reservoir volumetric variables and to reveal correlations among the variables; 2) the use of the Geo-anchored method to estimate simultaneously the number of oil and gas pools in the same play; and 3) the crossvalidation of assessment results from different methods. These techniques are illustrated by using an example of crude oil and natural gas resource assessment of the Sverdrup Basin, Canadian Archipelago. The example shows that when direct volumetric measurements of the untested prospects are not available, the MDP model can help derive unbiased estimates of the distribution parameters by using information from the discovered oil and gas accumulations. It also shows that an estimation of the number of oil and gas accumulations and associated size ranges from a discovery process model can provide an alternative and efficient approach when inadequate geological data hinder the estimation. Cross-examination of assessment results derived using different methods allows one to focus on and analyze the causes for the major differences, thus providing a more reliable assessment outcome.
\end{abstract}

Key words: Multivariate Discovery Process model, sampling bias correction, cross-validation, Geoanchored method

\section{Introduction}

Quality exploration decisions and portfolio management rely on a sound estimation of petroleum potential in a region of interest. In this paper, we propose several techniques for improving the quality of petroleum resource assessment when the reservoir volumetric method is applied. Two methods, commonly used for play level petroleum resource assessment, include the volumetric approach and discovery process modeling. The volumetric approach, employing reservoir volumetric equation, is a method accepted widely by industry (Baker et al, 1986; Gehman et al, 1980; White et al, 1975) and government agencies (Lee and Wang, 1983; Crovelli and Balay, 1986; Brekke and Kalheim, 1996; Schmoker and Klett, 2000; Attanasi and Charpentier, 2007). There is a widely held, but illusory belief that volumetric assessment is either more desirable or more reliable than discovery process model assessment. This belief arises because the geological and geophysical observations considered by volumetric assessments are the same as those used to evaluate prospects and drilling locations. However, there are practical problems that may affect the applicability or reliability of the volumetric assessment. The first problem is associated with

*Corresponding author. email: Zhuoheng.Chen@NRCan-RNCan.gc.ca Received August 19, 2008 the availability and comprehensiveness of the required data. Typically the geoscience data are incomplete and observations must be augmented by extrapolations or supplemented by analogies and inferences. Geographically comprehensive seismic and well data sets, like the Sverdrup Basin, are not generally available for most frontier areas. Second, aspects of prospect volumes, reservoir parameters and trap fill proportion must be estimated from either geographically limited data sets or appropriate analogs. An estimation of these parameters directly from the observations may result in too optimistic results because the data generation process represented by exploration drilling is biased (Kaufman et al, 1975; Lee and Wang, 1985). Fig. 1 is an example from Devonian reef play of the Rainbow Sub-basin, Western Canada Sedimentary Basin (WCSB), showing decline trends of major reservoir volumetric variables used in potential resource assessment by a reservoir volumetric approach. Third, interdependency between volumetric variables is commonly observed during data analysis for petroleum resource assessment at prospect and play levels (Lee et al, 1990; Kaufman, 1996). However, the estimation of petroleum accumulation size distribution using reservoir volumetric approach assumes that the geological variables are statistically independent (throughout this paper, unless otherwise specified, accumulation is used to represent either pool or field). Ignoring the correlation 
may lead to a biased result (Chen et al, 1994; 2007). Fig. 2 displays the observed correlation between reservoir porosity and gas saturation in the same reef play in WCSB. Fourth, the volumetric method requires an independent estimation of the number of accumulations. This number is commonly
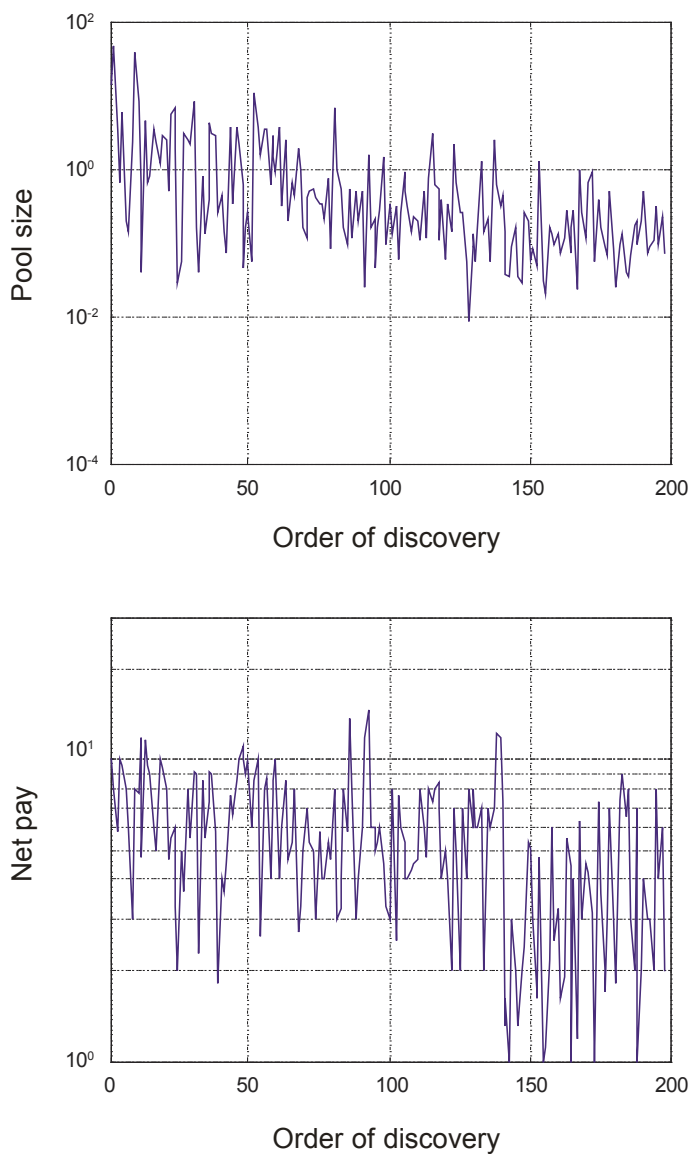

formulated as the product of the probability of petroleum occurrence and the total number of prospects that must be inferred because of the geometry of the seismic grid (Kaufman, 1994), both of which are commonly estimated subjectively.
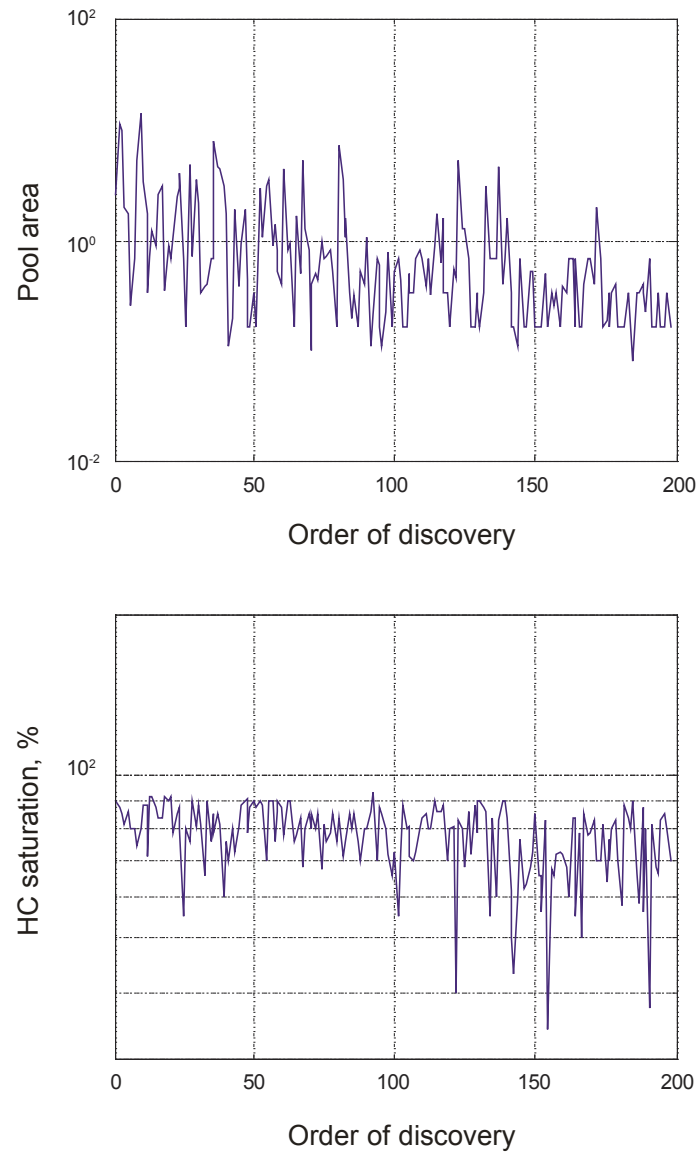

Fig. 1 Decline trends of major reservoir volumetric variables used in potential resource assessment by a reservoir volumetric approach, Devonian reef play of the Rainbow Sub-basin, Western Canada Sedimentary Basin (WCSB)

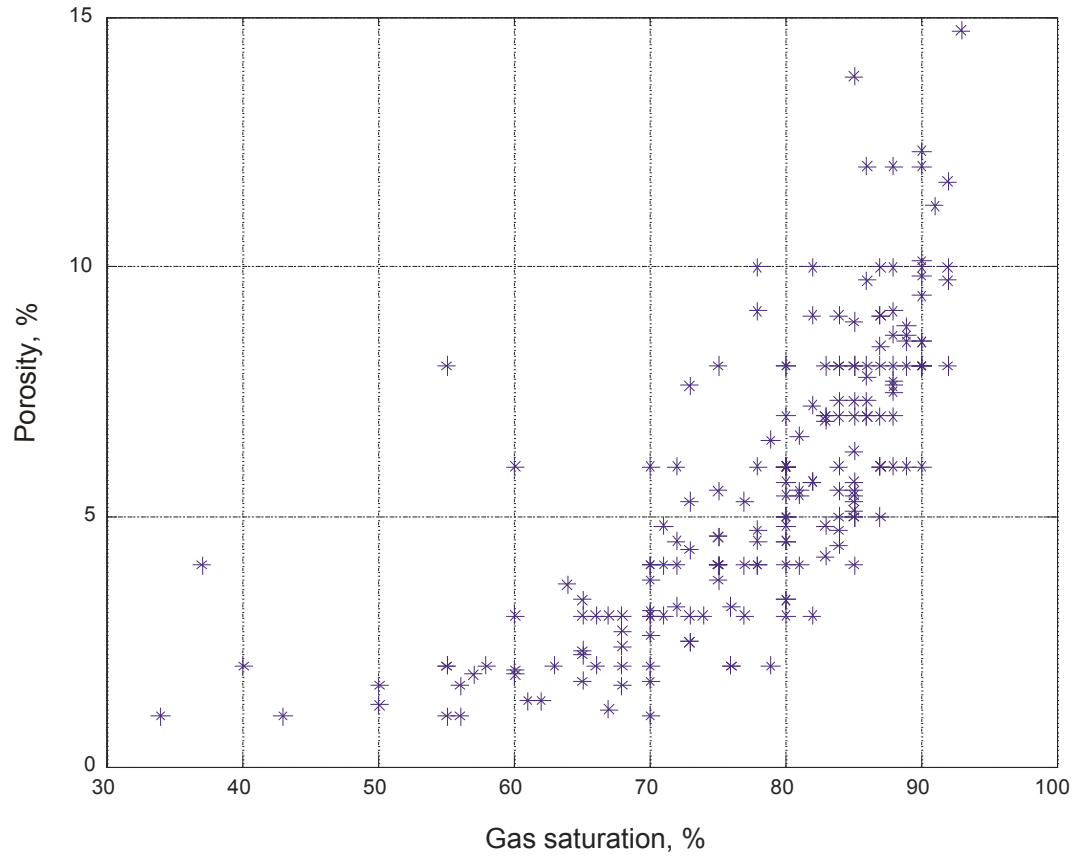

Fig. 2 Observed correlation between reservoir porosity and gas saturation in the same reef play in the WCSB 
If sufficient discoveries exist, it is possible to use a discovery process method that considers the size and order of the discoveries to infer the undiscovered play potential and remaining accumulation sizes (e.g., Arps and Roberts, 1958; Drew and Schuenemeyer, 1993; Lee and Wang, 1985; Kaufman, 1986; Chen et al, 1997; Chen and Sinding-Larsen, 1999; Sinding-Larsen and Xu, 2005; Logan, 2005). Discovery process models are popular among government agencies and research institutions (Kaufman et al, 1975; Lee and Wang, 1985; Lee, 1993; Drew and Schuenemeyer, 1993; Chen, 1993; Lee, 1998). A few major oil companies also apply discovery process models in their assessment of petroleum resources at the play level (Arps and Roberts, 1958; Grace, 1988; Coustau et al, 1988; Chen et al, 1997; Meneley et al, 2003; Logan, 2005). The popularity of this type of method amongst government agencies and research institutions derives from the facts that: 1) data requirement is minimal (only a discovery sequence is needed); and 2) play potential and the number of pools are determined simultaneously by statistical inferences, eliminating the need for both subjective analogies and extrapolations. This type of approach avoids direct use of geological data. The lack of an explicit link with geological controls has been the main focus of criticism (Kaufman et al, 1988; Grace, 1988). Problems relating to the application of the discovery model often arise from either an improper play definition or insufficient information in the discovery sequence for conducting statistical inferences. This method can only be applied to established plays where there are sufficient discoveries.

Each approach has its advantages and weaknesses while producing comparable types of outcome. A combined application of reservoir volumetric approach and discovery process model to the same play allows one to overcome the limitations of individual methods. In this paper, we propose several techniques to address the problems in the volumetric approach. These include:

1) The use of the Multivariate Discovery Process Model (MDSCV) (Lee and Gill, 1999) to obtain unbiased distribution parameters of reservoir volumetric variables and ascertain the correlation among these variables. In many cases, direct measurements of the dimensional parameters of the untested prospects are unavailable. The volumetric parameters have to be estimated from observations of discovered oil and gas accumulations.

2) The estimation of the number of oil and gas accumulations simultaneously in the same play using a discovery process model where there is insufficient geological and exploration data available for performing a play risk analysis and determining the number of accumulations.

3) Cross-validation of assessments by comparing the predictions derived using different methods.

\section{Methods description}

\subsection{Reservoir volumetric approach}

The reservoir volumetric approach has been widely used in petroleum resource assessment at play level (White et al, 1975; Gehman et al, 1980; Lee and Wang, 1985; Baker et al,
1986; Crovelli and Balay, 1986; Brekke and Kalheim, 1996; Sinding-Larsen and Chen, 1996). By the reservoir volumetric approach, two fundamental components, a size distribution and number of petroleum accumulations, must be estimated so that the play resource can be calculated. Using the reservoir volumetric equation, the in-place accumulation size, $Z$, can be expressed in the following relation:

$$
Z=C^{*} A^{*} T^{*} \phi^{*} S^{*} G^{*} H V F
$$

where $A$ is the pool closure area, $T$ is the net pay, $\phi$ is porosity, $S$ is petroleum saturation, $G$ is the trap geometric factor, $H V F$ is the reciprocal of the petroleum formation volume factor and $C$ is a unit conversion factor. For a petroleum play with $N$ pools, let the six reservoir volumetric variables in Eq. (1) be random variables $v_{i}, i=1,2, \ldots, 6$, in the form of log-normal distributions. The pool size labeled $k$ can then be written in the following form:

$$
Z_{k}=C \prod_{i=1}^{6} v_{k i}
$$

The product of several lognormal random variables is still log-normally distributed, and accumulation size, $Z$, is a random variable with a probability density function of:

$$
f(z)=\frac{1}{\sqrt{2 \pi} \sigma z} \exp \left\{-\frac{(\ln (z)-\mu)^{2}}{2 \sigma^{2}}\right\}
$$

where,

$$
\sigma^{2}=\sum_{i=1}^{6} \sigma_{i}^{2}+2 \sum_{i=1}^{6} \sum_{j=1}^{6} \sigma_{i j} \quad i \neq j
$$

and

$$
\mu=\ln (C)+\sum_{i=1}^{6} \mu_{i}
$$

and $\mu_{i}, \sigma_{i}^{2}$, and $\sigma_{i j}$ denote the log normal parameters of the six volumetric variables. The expected play potential can then be expressed in the following form (Lee, 2008):

$$
T=N \exp \left\{\mu+\sigma^{2} / 2\right\}
$$

where $N=\varphi M$ is the total number of pools in the play, which is a product of probability of petroleum occurrence $\varphi$ and total number of prospects $M$ (Lee, 2008). The estimation of the probability of petroleum occurrence requires detailed geological and exploration information and is commonly estimated subjectively. Baker et al (1986) used exploration success rate to approximate $\varphi$. However, both the exploration success rate and the number of prospects may change with time. It is common that exploration success rate declines with exploration maturity (Cheng et al, 2000; Forman and Hinde, 1985), whereas number of prospects increases with intensity of exploration, particularly seismic grid density and resolution (Kaufman, 1994). It is also common that the dimensional measurements of both the untested and 
the unmapped prospects and their reservoir volumetric parameters, such as porosity, petroleum saturation and net pay etc., have to be inferred by analog of the drilled prospects, particularly the discovered petroleum reservoirs. As past exploration drilling often represents a biased sampling, the observations of reservoir volumetric variables are also biased. Unless pool size had no impact on the order of previous discoveries, the $\mu$ vector and covariance matrix derived from the observations can not be used directly in the volumetric formulation in Eq. (4).

\subsection{Assessment procedure using volumetric approach}

The volumetric estimation of petroleum resources in this application followed a five-step procedure:

a) Using a discovery process model to obtain both the numbers of pools and pool size distributions for both oil and gas separately, and the discoverability factor for sample bias correction;

b) Using the MDP model to obtain a unbiased parameter set of volumetric variables and construct pool size distributions for both crude oil and natural gas;

c) Validating the numbers of oil and gas pools derived from the discovery process model using available geological data, exploration outcomes and our understanding of the petroleum geology in the region;

d) Estimating the play oil and gas resources and individual oil and gas size distribution;

e) Validating the assessments by comparing with the predictions from the Geo-anchored method.

\section{Application example}

\subsection{Geological setting and exploration history}

To illustrate the application of the proposed techniques in petroleum resource assessment, the western Sverdrup Basin has been chosen. This frontier basin has numerous identified petroleum fields, an available regional seismic data base and an established regional geologic framework. The results of volumetric assessments and discovery process can be validated against available observations and knowledge of petroleum occurrence in the western Sverdrup Basin.

The Sverdrup Basin is a major extensional basin underlying the Queen Elizabeth Islands of the Canadian Arctic Archipelago. The regional petroleum geology has been summarized by Embry et al (1991) and Waylett and Embry (1993). The stratigraphy and structural geology of the area are described by Balkwill and Roy (1977), Balkwill et al (1982), Balkwill (1983), Embry (1991) and Harrison (1995). Petroleum exploration occurred in the Sverdrup Basin between 1969 and 1986. Unfavorable external factors, especially global economic pressures, ended exploration activities despite extraordinary exploratory success. The discovered petroleum fields are all located within a broad fairway extending from western Ellef Ringnes Island southwestward to northeastern Melville Island (Fig. 3). These structures, though diverse in their characteristics, comprise a single anticlinal petroleum play that was prospected effectively by using combinations of surface mapping, and onshore and offshore reflection

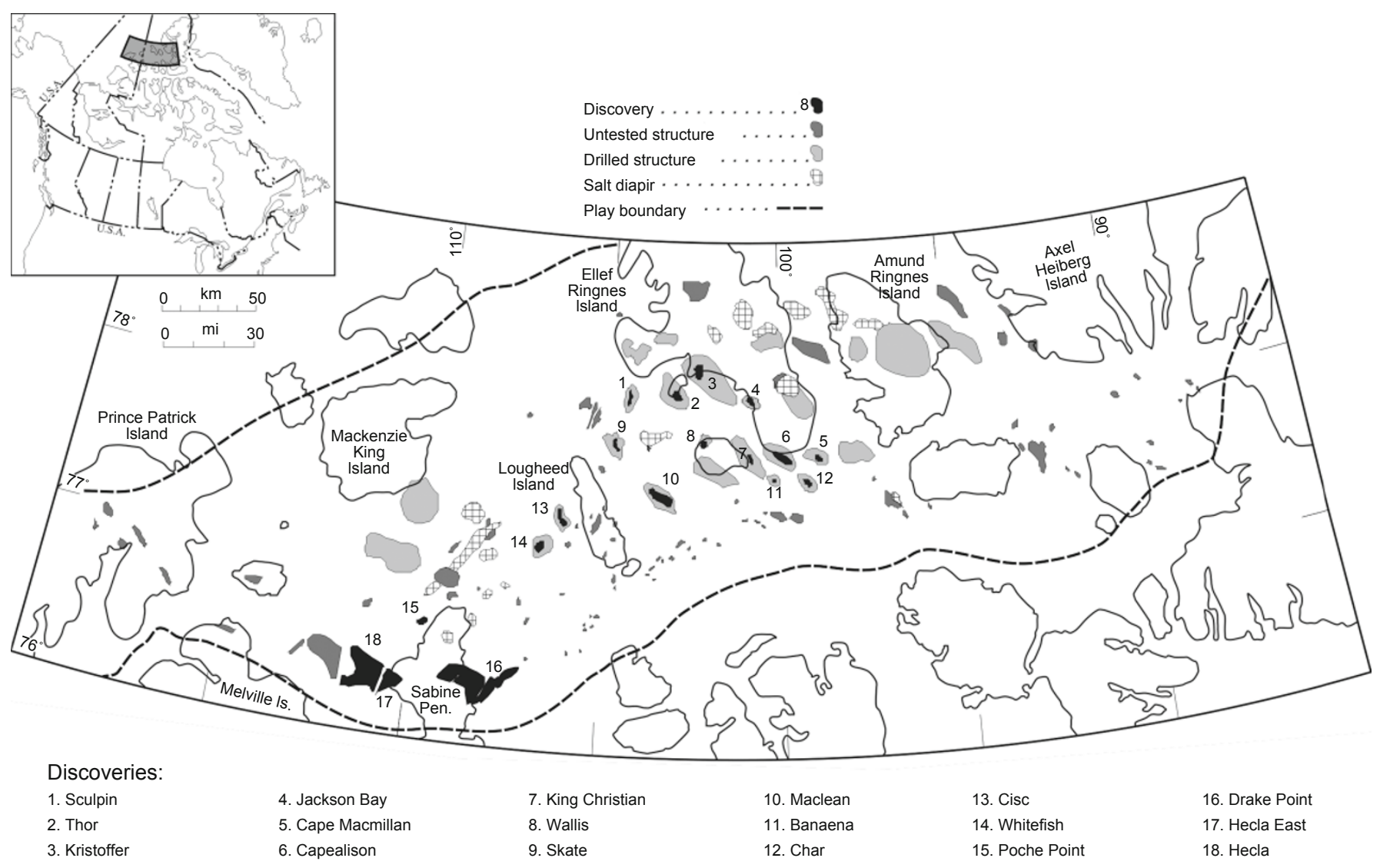

Fig. 3 Map showing the location of the study area, the discoveries and potential drilling targets in the Western Sverdrup Basin, Canadian Arctic Archipelago 
seismic surveys, the latter being acquired and interpreted under difficult conditions. Petroleum is found in a number of different stratigraphic units within the Mesozoic succession (Fig. 4). During 17 years of exploration, 119 wells drilled both onshore and offshore, in a most challenging environment led to discovery of the 21 major petroleum fields, comprising 8 oil and 25 gas pools. These accumulations have a total original in-place reserve of $294.1 \times 10^{6} \mathrm{~m}^{3}$ crude oil and 500.3 $\times 10^{9} \mathrm{~m}^{3}$ natural gas under standard conditions (Table 1).
For the purposes of this assessment, all pools and identified structures involving Mesozoic strata constitute a single, seismically definable, anticlinal play. This is consistent with the exploration philosophy pursued, a frontier anticlinal exploration effort. The current data base of widely separated wells and regional seismic profiles is insufficient to allow a more detailed set of play definitions. The geographic extent of the play is limited by the area underlain by potential reservoir rock within the available regional seismic grid.

Table 1 Discovery data in the Sverdrup Basin, Canadian Arctic Islands (Data up to 1992)

\begin{tabular}{|c|c|c|c|c|c|c|c|c|c|c|c|c|c|}
\hline Field name & $\begin{array}{l}\text { Disc. } \\
\text { date }\end{array}$ & $\begin{array}{c}\text { Total } \\
\text { reserve }\end{array}$ & $\begin{array}{c}\text { Total } \\
\text { oil }\end{array}$ & $\begin{array}{l}\text { Total } \\
\text { gas }\end{array}$ & $\begin{array}{l}\text { Is } \\
\text { oil }\end{array}$ & $\begin{array}{c}\text { Is } \\
\text { gas }\end{array}$ & $\begin{array}{l}\text { Ak } \\
\text { oil }\end{array}$ & $\begin{array}{l}\text { Ak } \\
\text { gas }\end{array}$ & $\begin{array}{l}\mathrm{He} \\
\text { oil }\end{array}$ & $\begin{array}{l}\mathrm{He} \\
\text { gas }\end{array}$ & $\begin{array}{c}\mathrm{He} \\
\text { gas* }\end{array}$ & $\begin{array}{l}\text { Sc.P } \\
\text { gas }\end{array}$ & $\begin{array}{l}\text { Sc.P } \\
\text { gas* }\end{array}$ \\
\hline West Drake & $69 / 09 / 02$ & 102.9 & 0.0 & 102.9 & 0.0 & 0.0 & 0.0 & 0.0 & 0.0 & 102.9 & 0.0 & 0.0 & 0.0 \\
\hline K. Christian & $70 / 10 / 25$ & 24.6 & 0.0 & 24.6 & 0.0 & 0.0 & 0.0 & 0.0 & 0.0 & 24.6 & 0.0 & 0.0 & 0.0 \\
\hline Kristoffer & $72 / 03 / 17$ & 55.8 & 0.0 & 55.8 & 0.0 & 0.0 & 0.0 & 0.0 & 0.0 & 55.8 & 0.0 & 0.0 & 0.0 \\
\hline Thor & $72 / 05 / 10$ & 13.9 & 0.0 & 13.9 & 0.0 & 0.0 & 0.0 & 0.0 & 0.0 & 13.9 & 0.0 & 0.0 & 0.0 \\
\hline West Hecla & $72 / 12 / 12$ & 98.6 & 0.0 & 98.6 & 0.0 & 0.0 & 0.0 & 0.0 & 0.0 & 98.6 & 0.0 & 0.0 & 0.0 \\
\hline Wallis & $73 / 02 / 02$ & 3.5 & 0.0 & 3.5 & 0.0 & 0.0 & 0.0 & 0.0 & 0.0 & 3.5 & 0.0 & 0.0 & 0.0 \\
\hline East Drake I-55 & $75 / 04 / 16$ & 12.4 & 0.0 & 12.4 & 0.0 & 0.0 & 0.0 & 0.0 & 0.0 & 12.4 & 0.0 & 0.0 & 0.0 \\
\hline East Hecla & $75 / 12 / 16$ & 1.4 & 0.0 & 1.4 & 0.0 & 0.0 & 0.0 & 0.0 & 0.0 & 1.4 & 0.0 & 0.0 & 0.0 \\
\hline Jackson Bay & $76 / 04 / 30$ & 39.7 & 0.0 & 39.7 & 0.0 & 0.0 & 0.0 & 0.0 & 0.0 & 39.7 & 0.0 & 0.0 & 0.0 \\
\hline Cape Allison & $78 / 03 / 15$ & 77.2 & 54.5 & 22.7 & 0.0 & 0.0 & 0.0 & 22.7 & 54.5 & 0.0 & 0.0 & 0.0 & 0.0 \\
\hline Roche Point & $78 / 03 / 18$ & 1.8 & 0.0 & 1.8 & 0.0 & 0.0 & 0.0 & 0.0 & 0.0 & 0.0 & 0.0 & 0.7 & 1.1 \\
\hline Char & $80 / 04 / 22$ & 10.9 & 5.4 & 5.4 & 0.0 & 0.0 & 5.4 & 0.0 & 0.0 & 5.4 & 0.0 & 0.0 & 0.0 \\
\hline Balaena & $80 / 04 / 27$ & 94.2 & 94.2 & 0.0 & 94.2 & 0.0 & 0.0 & 0.0 & 0.0 & 0.0 & 0.0 & 0.0 & 0.0 \\
\hline Whitefish & $80 / 05 / 15$ & 68.2 & 0.0 & 68.2 & 0.0 & 3.9 & 0.0 & 25.4 & 0.0 & 38.9 & 0.0 & 0.0 & 0.0 \\
\hline Skate B-80 & $81 / 04 / 04$ & 13.6 & 11.4 & 2.2 & 0.0 & 0.0 & 0.0 & 0.0 & 11.4 & 2.2 & 0.0 & 0.0 & 0.0 \\
\hline Skate C59 & $81 / 04 / 04$ & 28.3 & 14.9 & 13.4 & 0.0 & 0.0 & 0.0 & 0.0 & 14.9 & 13.4 & 0.0 & 0.0 & 0.0 \\
\hline Maclean & $81 / 04 / 27$ & 16.0 & 0.0 & 16.0 & 0.0 & 0.0 & 0.0 & 0.0 & 0.0 & 5.9 & 10.1 & 0.0 & 0.0 \\
\hline Cisco & $81 / 05 / 04$ & 114.7 & 111.2 & 3.5 & 0.0 & 0.0 & 105.0 & 0.0 & 6.2 & 3.5 & 0.0 & 0.0 & 0.0 \\
\hline Sculpin & $82 / 04 / 24$ & 2.7 & 0.0 & 2.7 & 0.0 & 0.0 & 0.0 & 0.0 & 0.0 & 2.7 & 0.0 & 0.0 & 0.0 \\
\hline Cape MacMillan & $83 / 04 / 12$ & 6.0 & 3.5 & 2.5 & 0.0 & 0.0 & 0.0 & 2.1 & 2.5 & 1.4 & 0.0 & 0.0 & 0.0 \\
\hline East Drake L-06 & $85 / 04 / 16$ & 8.1 & 0.0 & 8.1 & 0.0 & 0.0 & 0.0 & 0.0 & 0.0 & 8.1 & 0.0 & 0.0 & 0.0 \\
\hline Total & & 794.4 & 294.1 & 500.3 & 94.2 & 3.9 & 110.4 & 50.2 & 89.6 & 434.2 & 10.1 & 0.7 & 1.1 \\
\hline
\end{tabular}




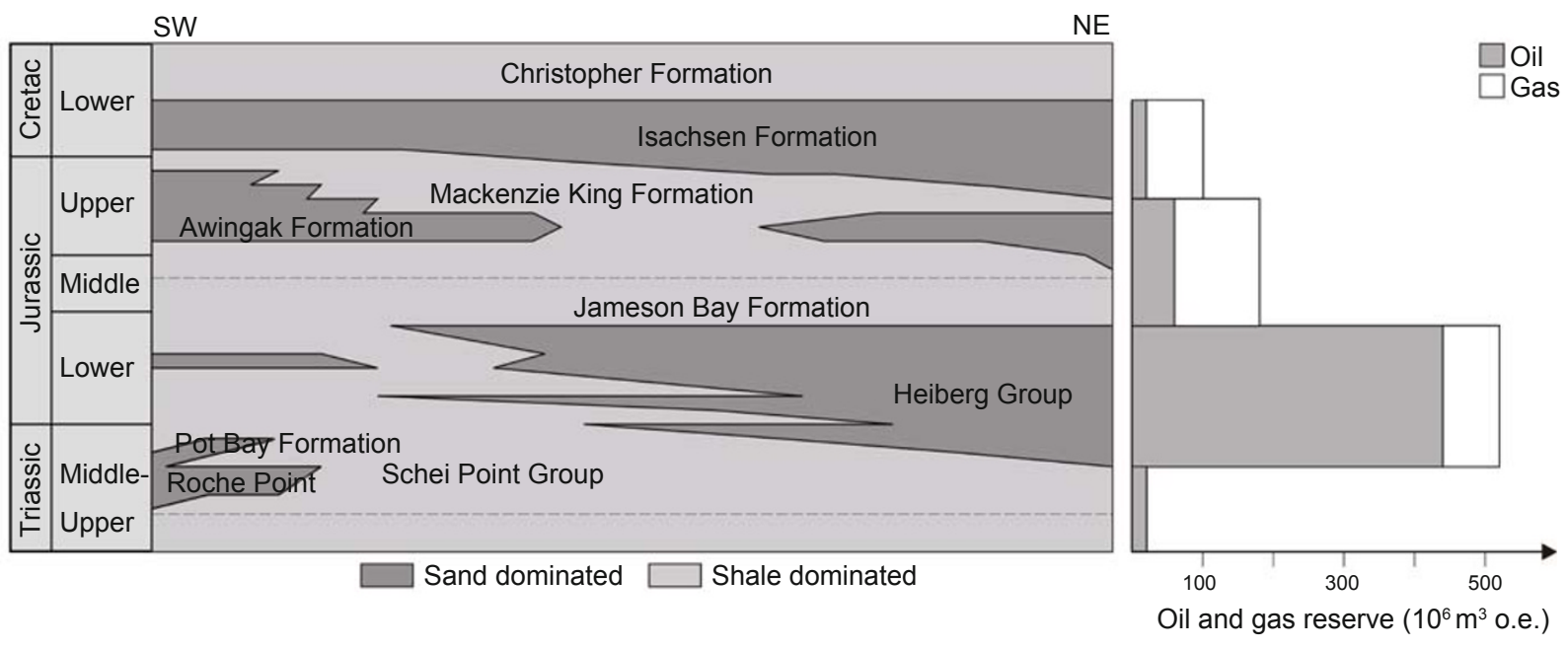

Fig. 4 Diagrammatic representation of the Mesozoic stratigraphic succession in western Sverdrup Basin (left). The stratigraphic distribution of discovered petroleum reserves (right) is indicated as oil equivalent $\times 10^{6} \mathrm{~m}^{3}$

\subsection{Discovery process model assessment}

In this study, we estimated the population properties of a natural group of oil and gas pools in a petroleum play, such as the total number of pools, the play potential and the pool size distribution using the Geo-anchored method (Appendix A). The reasons for choosing this method are threefold: 1) The shape of pool size distribution has been discussed for more than two decades (e.g., Schuenemeyer and Drew, 1983; Davis and Chang, 1989; Lee, 1993), and still the true shape of pool size distribution is difficult to judge. The Geo-anchored method uses a non-parametric approach where no assumption is made on the parent accumulation size distribution. 2) Logan (2005) has verified that Chen's Geo-anchored method (Chen, 1993) is identical numerically and mathematically to Bickle-Nair-Wang's non-parametric approach (Bickel et al, 1992), though derived using different estimators. The Geo-anchored method has been compared with other discovery process models (Lee and Gill, 1999). It appears that this method yields reliable results of play potential and number of accumulations in a petroleum play with results consistently lying between results obtained from the lognormal discovery process model developed at the Geological Survey of Canada (GSC) (Lee and Wang, 1985) and the discovery process model developed at the U.S. Geological Survey (USGS) (Drew and Schuenemeyer, 1993). 3) The Geo-anchored method estimates the oil and gas potential and number of oil and gas pools simultaneously without separating oil and gas in the same area into two plays. Traditionally, the GSC assessment procedure separates oil and gas pools into two different plays and estimates the properties of the population independently. It is common that oil and gas co-exist in nature as separate phases in a single pool. Sometimes the separation of oil and gas pools into two plays results in insufficient discoveries and loss of confidence in the original statistical inference. To overcome this dilemma, Lee (1998) proposed using the MDP model for the simultaneous estimation of oil and gas pool size distributions. However, this method cannot be applied to a play consisting of associated crude oil and gas accumulations that include pools containing either oil or gas exclusively, for which, the covariance between oil and gas pools may diminish (Lee et al, 1999).

In the western Sverdrup Basin, individual structural prospects may contain more than one pool. The exploration process focused on the structural prospect and so it is appropriate to use field size, rather than pool size, as the magnitude parameter in the inclusion probability estimation (Chen and Sinding-Larsen, 1999). The discovery sequence, the discovered field sizes ordered with respect to discovery date (columns 2 and 3, Table 1) is used to estimate both total petroleum potential and the total number of fields (Table 2). Given the estimated inclusion probabilities along with the discovered oil and gas pool sizes (columns 4 and 5, Table 1), the oil and gas resources and the numbers of oil and gas pools are then calculated separately. Although the Geo-anchored method is a non-parametric model, it is not unusual that the empirical distribution from the Geo-anchored estimation fits well with a truncated log-normal model (e.g., Chen et al, 1997). To be comparable with results from the reservoir volumetric approach, the empirical distributions of the oil and gas pools are fitted with a truncated log-normal model. Fig. 5 shows the estimated empirical pool size distributions from the Geo-anchored method. Setting a minimum pool size of $0.5 \times 10^{6} \mathrm{~m}^{3}$ oil equivalent, Monte Carlo simulations of the truncated log-normal pool size distributions with estimated numbers of oil and gas pools were implemented to generate pool by rank diagrams for both the oil and gas pools respectively. In the simulation, the number of oil pool is extended to 29 based on the fitted log-normal model instead of 26 in Table 2 because of the assumption of minimum pool size. However, the number of 110 natural gas pools was kept unchanged, because the smallest gas pool is $0.74 \times 10^{6}$ $\mathrm{m}^{3}$ oil equivalent, very close to the minimum pool size. The pool size by rank diagrams constrained by the discoveries for the oil and gas resources using matching process (Lee and Wang, 1985) are displayed in Fig. 6(a) and 6(b) respectively, 
Table 2 Summary of estimated pool numbers and potentials in size classes from the Geo-anchored method

\begin{tabular}{|c|c|c|c|c|c|c|}
\hline $\begin{array}{c}\text { Size class } \\
\text { (oil: } 10^{6} \mathrm{~m}^{3} \text {, gas: } 10^{9} \mathrm{~m}^{3} \text { ) }\end{array}$ & $\begin{array}{l}\text { Oil pool } \\
\text { number }\end{array}$ & Oil potential & $\begin{array}{l}\text { Gas pool } \\
\text { number }\end{array}$ & Gas potential & $\begin{array}{l}\text { Oil\&gas field } \\
\text { number }\end{array}$ & Oil\&gas potentia \\
\hline $1-2$ & 0.0 & 0.0 & 31.1 & 49.2 & 31.1 & 49.2 \\
\hline $2-4$ & 7.2 & 18.1 & 34.9 & 106.7 & 21.3 & 65.0 \\
\hline $4-8$ & 5.2 & 28.4 & 5.2 & 28.5 & 7.2 & 43.6 \\
\hline $8-16$ & 7.8 & 100.5 & 23.1 & 285.1 & 29.8 & 362.2 \\
\hline $16-32$ & 0.0 & 0.0 & 5.4 & 129.8 & 6.6 & 174.4 \\
\hline $32-64$ & 2.0 & 109.6 & 5.0 & 236.6 & 5.0 & 236.6 \\
\hline $64-128$ & 3.6 & 365.9 & 5.7 & 508.6 & 11.3 & 1035.9 \\
\hline Total & 25.9 & 622.5 & 110.4 & 1344.4 & 112.3 & 1966.9 \\
\hline
\end{tabular}
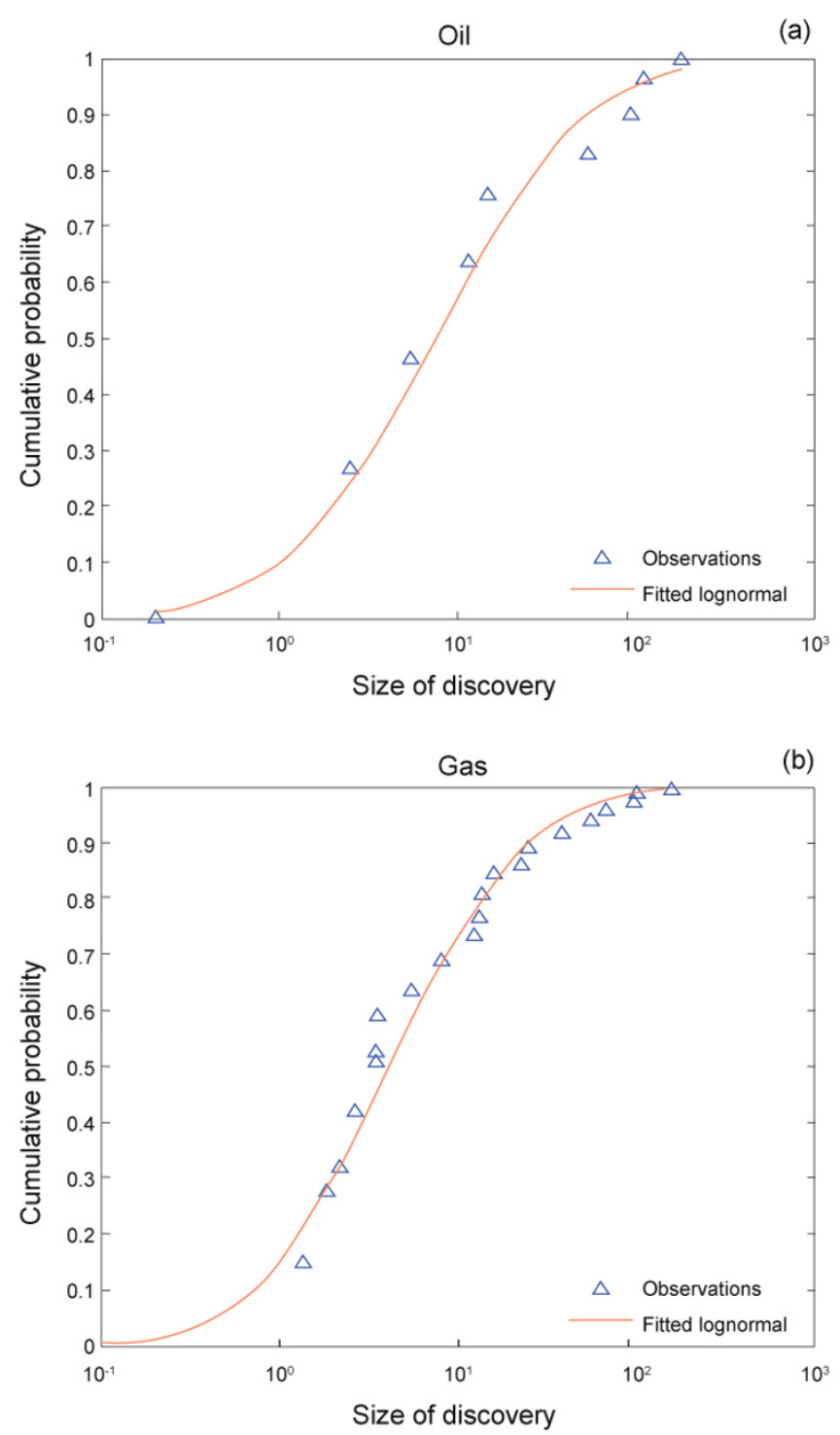

Fig. 5 Oil pool size (a) and natural gas (b) distributions estimated by the Geo-anchored method discovery process model and truncated lognormal fits. Oil pool size in $10^{6} \mathrm{~m}^{3}$ in-place and gas pool size in $10^{9} \mathrm{~m}^{3}$ in-place

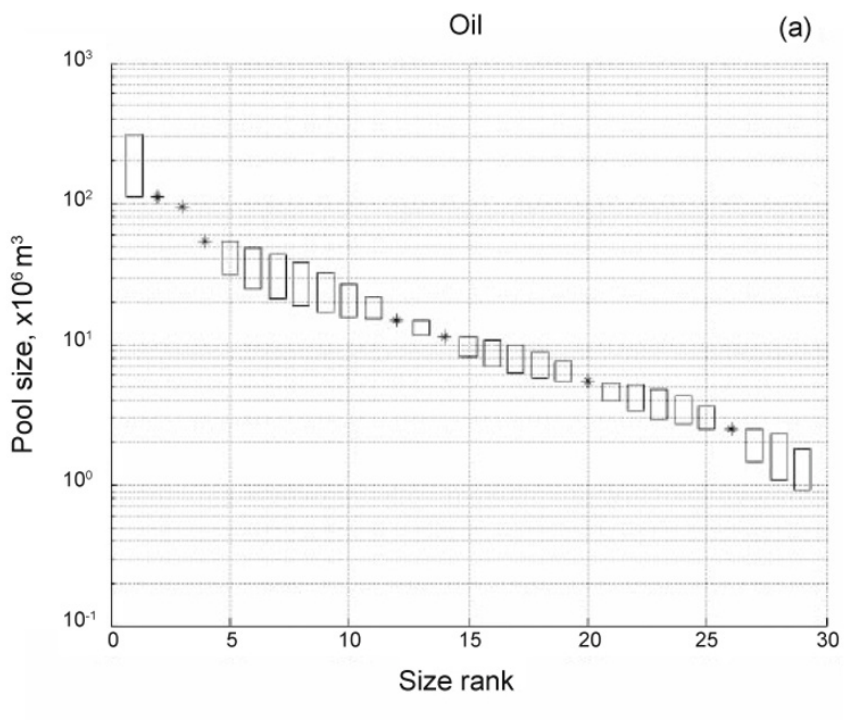

Gas

(b)

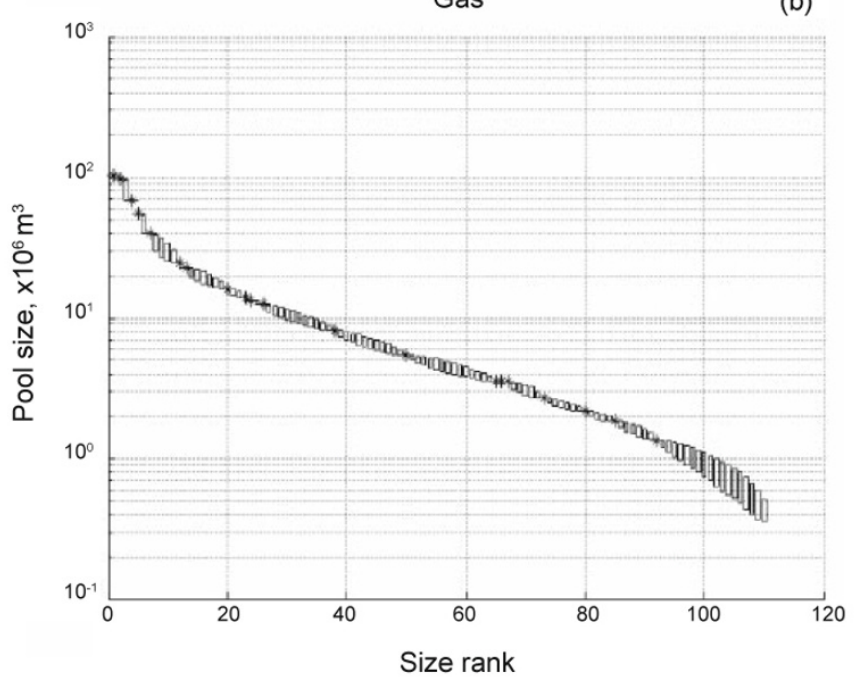

Fig. 6 Oil (a) and natural gas (b) pool size by rank plots based on the Geo-anchored method subsequent to the matching of discovered oil pools (crosses) with predicted pool size distributions. Undiscovered pool size ranges are indicated by the open rectangles 
Table 3 Initial assessment results comparison of the Geo-anchored method and the volumetric approach. No restriction applied to the volumetric approach. Units: oil in $10^{6} \mathrm{~m}^{3}$, and gas in $10^{9} \mathrm{~m}^{3}$

\begin{tabular}{ccccccc}
\hline Potential distribution & $5 \%$ & $25 \%$ & $50 \%$ & $75 \%$ & $95 \%$ & Mean \\
Oil (Geo-anchored) & 915.1 & 771.7 & 673.1 & 620.7 & 588.4 & 675.5 \\
Oil (Volumetric) & 928.6 & 850.2 & 775.5 & 702.1 & 660.2 & 754.6 \\
Gas (Geo-anchored) & 1261.1 & 1219.9 & 1187.4 & 1157.6 & 1124.9 & 1178.1 \\
Gas (Volumetric) & 1900.8 & 1666.8 & 1496.1 & 1360.4 & 1209.7 & 1518.1 \\
\hline
\end{tabular}

showing the reduced uncertainty ranges of the undiscovered individual pools. The expected gas resource for the modeled anticline play of the Sverdrup Basin derived using the Geoanchored method, is $1,178.1 \times 10^{9} \mathrm{~m}^{3}$ gas in-place and $675.5 \times 10^{6} \mathrm{~m}^{3}$ crude oil in place. The percentiles of the crude oil and natural gas resource distributions are listed in Table 3.

\subsection{Validation of the estimated number of oil and gas pools}

The discovery process predicted 112 petroleum fields, containing 139 pools, of which 29 are crude oil and 110 are natural gas pools with sizes equaling or exceeding the minimum oil and gas pool size. To validate the estimated numbers of oil and gas pools, it requires the determination of the total number of prospects, both mapped - drilled and remaining - and unmapped. This number, when combined with the overall exploratory risk should give a general idea of the expected number of pools. There are about 150 mapped prospects, including salt diapirs (Fig. 3). The average seismic grid spacing is approximately $10 \mathrm{~km} \times 5 \mathrm{~km}$. We assume, but recognize as optimistic, a perfect detecting capability for the available seismic survey. As such the probability of missing a geophysical anomaly comparable in size to the smallest discovered pool, $4.0 \mathrm{~km}^{2}$, is estimated to be between $0.18-0.48$, depending on anomaly geometry and orientation (Kaufman, 1994; Chen et al, 2000). The probability of not detecting a geophysical anomaly of $1.0 \mathrm{~km}^{2}$ is between 0.65 0.75 , depending on anomaly geometry and orientation. Prospects with areas equal to or greater than $1.0 \mathrm{~km}^{2}$ may be economically significant, in light of the known reservoir parameter distributions and considering that each successful structural test has resulted in an overall average of 1.5 pools. Therefore, the total number of sizable prospects could be much greater than 150 .

Exploration of 37 prospects has resulted in the discovery of 21 petroleum fields (Fig. 3). This indicates an overall exploration success rate of about $50 \%$. In addition, the large closures in the Ellef Ringnes Island area may not be adequately tested by available wells. Petroleum fill is generally about $10 \%$ of the closure area in discovered pools (Waylett and Embry, 1993). This suggests that subsidiary culminations on large structures may provide untested potential within the boundaries of large prospects defined previously (Waylett and Embry, 1993). On the other hand, we also realized that the exploration success rate may decline with increase in exploration maturity as is the case for many well-explored basins (Cheng et al, 2000; Forman and Hinde, 1985). It appears that a significant geographic variation in exploration success rate exists. Overlying the "petroleum kitchen" between Sabine Peninsula, Melville Island and Ellef Ringnes Island (Brooks et al, 1992; Chen et al, 2002; Chen and Osadetz, 2006), the exploration success rate is high. In contrast, the rate of success is much lower in outlying areas. Considering the regional seismic grid, its age and quality, it is possible that many medium and small fields remain unidentified in this area. By analyzing available geological and exploration data, the inference of 139 pools with sizes equaling or exceeding the smallest discovered oil and gas pools by the Geo-anchored method appears to be reasonable and consistent with both geological setting and exploration history data.

\subsection{Reservoir volumetric approach assessment}

As in this study, no direct measurements with respect to the dimension of untested prospects are available; the reservoir volumetric parameters were estimated from the discovered pools. It is necessary to test for and correct the impact of sampling bias and correlation among reservoir variables on the estimated accumulation size distribution. The Multivariate Discovery Process model (Lee, 1998; 2008) is used for such corrections resulting in the maximum likelihood estimates (MLE) of $\mu$ vector, covariance matrix and correlation coefficient matrix of reservoir volumetric variables (Tables 4(a), (b), (c)). The reduction in $\mu$ values of the gas pool size distribution indicates a correction of the sampling bias (Table 4(a)). Conversely, but consistently, the maximum likelihood estimates of covariance matrix values are higher than those computed directly from observations (Table 4(b)). In contrast, oil pool size does not have significant impact on the order of oil discovery (Table 1). This is consistent with the apparently random nature of oil pool discovery. The oil pool $\mu$ vectors and covariance matrix from both the MDSCV and the observations are identical.

Following the correction of reservoir volumetric distribution parameters for sampling bias, the resulting covariance matrix and $\mu$ vector are used to formulate the crude oil and natural gas pool size distributions. Four random variables, pool area, net pay, porosity and petroleum saturation, are treated as multivariate log-normal distributions; while formation volume factor and volumetric geometric factor are treated as independent random variables. The formation volume factor for natural gas is a function 
of reservoir temperature and pressure, both of which are functions of reservoir depth (Crovelli and Balay, 1986). The estimated pool size distributions are combined with the numbers of pools to calculate the play oil and gas resources and construct pool size by rank diagrams. As discussed below, we use the numbers of crude oil pools, 29, and natural gas pools, 110 estimated by the Geo-anchored method. This allows better comparison of the results of the two assessments while avoiding the subjective estimation of exploration risk and inference of prospect numbers. Monte Carlo method is applied to derive the oil and gas resource distributions as well as individual pool sizes and their uncertainty ranges. By matching the predicted with discovered pools (Lee and Wang, 1985), the resulting pool size by rank for both oil and gas pools are shown in Fig. 7(a) and 8(a). The expected resource values at 5 th and 95 th percentiles are $928.6 \times 10^{6} \mathrm{~m}^{3}$ to 660.2 $\times 10^{6} \mathrm{~m}^{3}$ crude oil and $1,900.8 \times 10^{9} \mathrm{~m}^{3}$ to $1,209.7 \times 10^{9} \mathrm{~m}^{3}$ natural gas. The median resource values are $775.5 \times 10^{6} \mathrm{~m}^{3}$ crude oil and $1,496.1 \times 10^{9} \mathrm{~m}^{3}$ natural gas respectively. The mean values of the oil and gas resource are $754.6 \times 10^{6} \mathrm{~m}^{3}$ and $1,518.1 \times 10^{9} \mathrm{~m}^{3}$, respectively (Table 3 ).

Table 4(a) $\mu$ vector and Maximum Likelihood Estimate (M.L.E). of $\mu$ vector (gas pools)

\begin{tabular}{ccc}
\hline Variables & $\mu$ (data) & $\mu$ (M.L.E.) \\
Closure area & 7.7977 & 7.3241 \\
Net pay & 2.8176 & 2.5495 \\
Porosity & -1.7247 & -1.7400 \\
Saturation H & -0.3900 & -0.44278 \\
\hline
\end{tabular}

Table 4(b) Covariance matrix and M.L.E. (in bracket) of covariance matrix (gas pools)

\begin{tabular}{clll}
\hline Variables & \multicolumn{3}{c}{ Covariance matrix } \\
\hline Closure area & $1.4936(1.5263)$ \\
\hline Net pay & $.3130(.3315)$ & $.7296(.7400)$ \\
\hline Porosity & $-.0243(-.0232)$ & $-.0096(-.0090)$ & $.0260(.0260)$ \\
\hline Saturation H & $.0676(.0712)$ & $.0759(.0780)$ & $.0074(.0076)$ \\
\hline
\end{tabular}

Table 4(c) Correlation matrix and M.L.E. (in bracket) of correlation matrix (gas pools)

\begin{tabular}{ccccc}
\hline Variables & \multicolumn{5}{c}{ Correlation matrix } \\
\hline Closure area & 1.0000 & & \\
\hline Net pay & $.2999(.3119)$ & 1.0000 & \\
\hline Porosity & $-.1233(-.1167)$ & $-.0699(-.0651)$ & 1.0000 & \\
\hline Saturation H & $.38527(.3978)$ & $.6192(.6254)$ & $.3221(.3238)$ & 1.0000 \\
\hline
\end{tabular}

\subsection{Improving assessment results through cross- validation}

A comparison indicates that while the petroleum resource potentials obtained by using the discovery process and the volumetric methods are generally similar, there are some discrepancies (Table 3). In the crude oil resource estimation, the discovery process analysis indicates an expected play resource of $675.5 \times 10^{6} \mathrm{~m}^{3}$, whereas the volumetric method indicates $747.6 \times 10^{6} \mathrm{~m}^{3}$, about $11 \%$ greater than the Geoanchored estimate. For natural gas, the discovery process analysis indicates an expected play resource of $1,178.1 \times 10^{9}$ $\mathrm{m}^{3}$, whereas the volumetric method indicates $1,518 \times 10^{9} \mathrm{~m}^{3}$ (Table 3). Other than for the expected value, the natural gas potential distribution derived volumetrically is generally $20 \%$ greater than that from the discovery process method (Table 3) with a larger uncertainty range.

Most discrepancies arise from differences in assumptions with respect to pool size distributions of the two methods. The volumetric approach assumes a log-normal distribution. In contrast the Geo-anchored method makes no assumption regarding the shape of the parent pool size distribution though the predicted accumulation size distribution fits well with a truncated log-normal model. Bearing the differences in assumptions in mind, a cross validation can be performed to check geological reality: whether the Geo-anchored method under-estimate the oil and gas resource potentials or the volumetric approach over-estimate the resource potentials.

A comparison between the accumulation-size by rank plots derived from the two methods indicates the volumetric approach suggesting a more optimistic figure with two largest oil pools remaining to be discovered. The reality check indicates that an undiscovered oil pool as large as the 5th percentile of the largest pool predicted by the volumetric method (Fig. 7(a)) requires a physical volume more than two times greater than that of the largest discovered oil pool. Geological, geophysical and exploration history information all suggest this is unlikely. Considering geoscience and exploration history data, we may restrict the largest undiscovered oil pool to, for example, be no larger than $200 \times 10^{6} \mathrm{~m}^{3}$. On the other hand, the fact that the Geoanchored and volumetric approaches generate two similar oil pool size distributions with a shift pins down the possibility of overestimated volumetric parameters in the volumetric approach as we assumed a random discovery process for the oil pools. This assumption of a random data generation process for oil pools may not be true as the discovery process model indicates the impact of petroleum field size (oil and gas) on the order of discovery. As part of a field, oil pools can not be completely independent from gas pools though the discovery sequences for the two are different in this play. Using the pool size constraint and a revised formation volume factor, the re-calculation produced a mean of 699.9 $\times 10^{6} \mathrm{~m}^{3}$, which is very close to the mean of the Geoanchored estimate and the size of the largest undiscovered oil pool is slightly smaller than the one derived from the Geoanchored method (Fig. 7(b)). If a reality check comes with the possibility of finding an oil pool with the largest pool size indicated by the Geo-anchored method, the results from 
the volumetric approach may under-estimate the oil potential in the largest undiscovered pool. However, the median crude oil resources by the Geo-anchored and volumetric approaches are $673.1 \times 10^{6} \mathrm{~m}^{3}$ and $698.7 \times 10^{6} \mathrm{~m}^{3}$ respectively (Table 5), and the differences from the two approaches are insignificant.

Table 5 Assessment result comparison of the Geo-anchored method and the volumetric approach. Restrictions applied to the volumetric approach. Units: oil in $10^{6} \mathrm{~m}^{3}$, and gas in $10^{9} \mathrm{~m}^{3}$

\begin{tabular}{ccccccc}
\hline Potential distribution & $5 \%$ & $25 \%$ & $50 \%$ & $75 \%$ & $95 \%$ & Mean \\
Oil (Geo-anchored) & 915.1 & 771.7 & 673.1 & 620.7 & 588.4 & 675.5 \\
Oil (Volumetric) & 842.3 & 766.2 & 698.7 & 644.4 & 607.8 & 699.9 \\
Gas (Geo-anchored) & 1261.1 & 1219.9 & 1187.4 & 1157.6 & 1124.9 & 1178.1 \\
Gas (Volumetric) & 1276.5 & 1235.4 & 1202.8 & 1171.2 & 1135.7 & 1203.8 \\
\hline
\end{tabular}

(a)

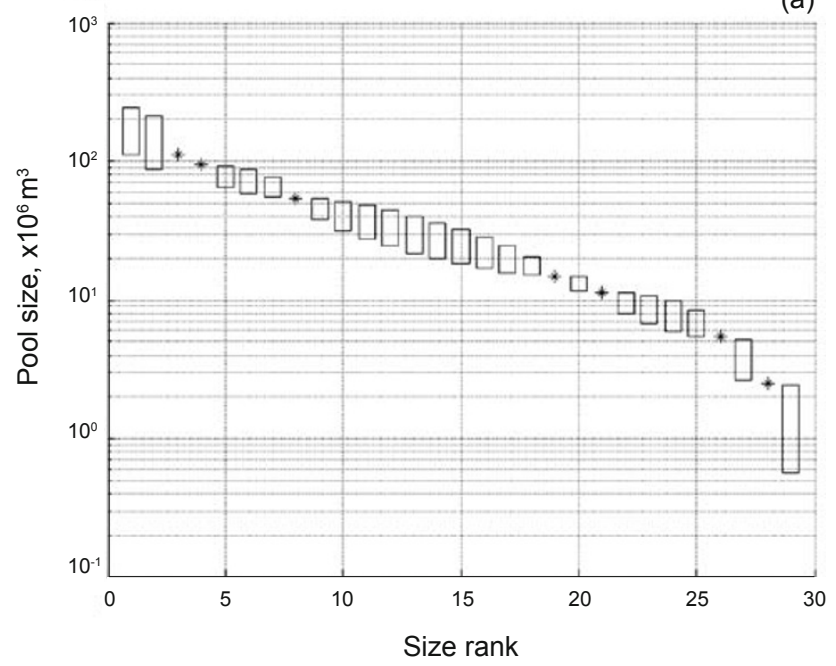

(b)

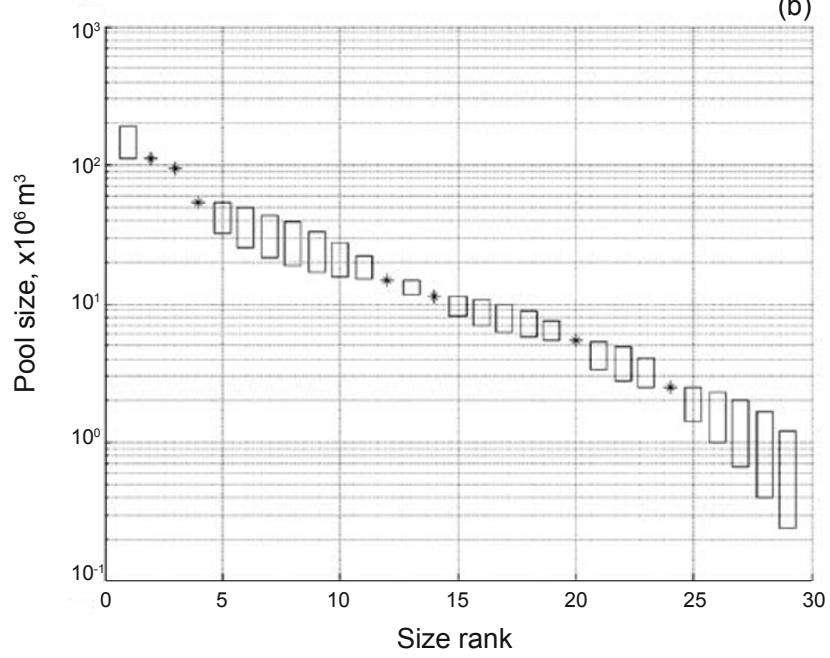

Fig. 7 Oil pool size by rank plot estimated using the volumetric method subsequent to the matching of discovered oil pools (crosses) with predicted oil pool size distributions. Undiscovered oil pool size ranges are indicated by the open rectangles. (a): Results shown are unconstrained by the geological implications of predicted undiscovered oil pool sizes (see text). (b): Results shown are constrained by the geological implications of predicted undiscovered oil pool sizes (see text)
For the natural gas assessment, the predicted sizes of the largest undiscovered pools account for most of the differences. The volumetric approach predicts the two largest gas pools remaining to be discovered (Fig. 8(a)), while the discovery process model suggests that the largest gas pool has already been discovered (Fig. 6(b)). An analysis of available geological data indicates that all untested targets are too small to accommodate another large gas pool with the same magnitude of the largest discovered gas pool, which suggests the necessity of truncating the gas pool size distribution from the volumetric approach to $150 \times 10^{9} \mathrm{~m}^{3}$, so that the predicted largest undiscovered gas pool is smaller than the existing largest gas discovery in the play. The revised calculation gives a very similar characterization of the natural gas resource potential like that from the Geo-anchored method (Table 5).

Fundamental differences in assumption regarding the underlying parent distributions also account for differences between the estimates directly from the Geo-anchored method and the Monte Carlo simulations. For example, 110 pools were inferred from the Geo-anchored method to represent the number of gas pools larger than or equal to the smallest gas pool discovered and does not present the total number of gas pools in the anticlinal play of western Sverdrup Basin. However, the number of 110 gas pools is treated as the total number of gas pools and no restriction is considered with respect to the smallest discovery in the Monte Carlo simulation. Consequentially, a considerable fraction of the pools predicted using Monte Carlo simulation are smaller than the smallest discovered oil and natural gas pools, which results in a slightly smaller mean (compare Table 2 and 3 ). If volumetric simulation restricts all 110 gas pools to be no smaller than the smallest discovered gas pool, which is equivalent to truncating the log-normal distribution at a pool size to the smallest discovered pool size, the simulated pool size distribution represents a set of more comparable results with that from the Geo-anchored method. From this analysis, one may note that independently estimated number of pools alone does not provide sufficient information for determining play resource and individual pool sizes. The number of pools must come along with an associated size range. It is also 
true that the number of pools derived from a geological play analysis could be an independent estimate if no attention is paid to how the number is derived in relation with the associated size of untested targets.

In general, both methods can have a large uncertainty range for the predicted resource potentials. However, the application of the matching process (Lee and Wang, 1985) allows the sizes of discovered pools being used to constrain the uncertainty ranges of the undiscovered pools, thus reducing the uncertainty ranges of the undiscovered pools as well as the difference in the uncertainties of the total resource potential from the two methods (Figs. 6-8).

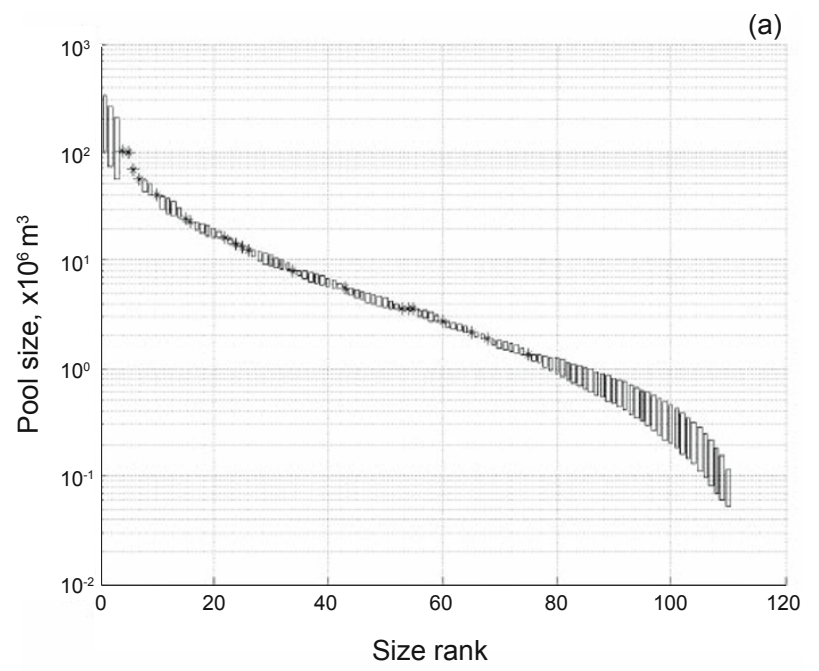

(b)

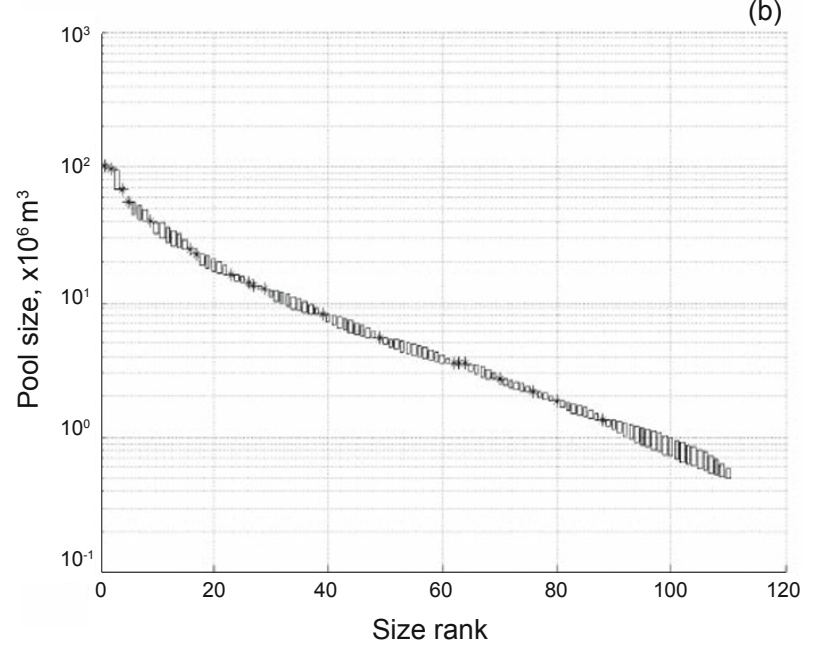

Fig. 8 Gas pool size by rank plot estimated using the volumetric method subsequent to the matching of discovered gas pools (crosses) with predicted gas pool size distributions. Undiscovered gas pool size ranges are indicated by the open rectangles. (a): Results shown are unconstrained by the geological implications of predicted undiscovered gas pool sizes (see text). (b): Results shown are constrained by the geological implications of predicted undiscovered gas pool sizes

\section{Summary}

Play petroleum resource calculation using reservoir volumetric approach involves two independent estimations, pool/field size distribution and the number of pools/fields.
The major obstacle in inference of a pool size distribution is the estimation of distribution parameters due to the nature of biased sampling processes in exploration and availability of volumetric measurements of untested (including unmapped) prospects. It is possible to infer the distribution parameters from discovered pools using a multivariate discovery process model, like the GSC's MDSCV. Usually the discovery data is available to the public and the reservoir parameters and volumetric variables are well studied. Those distribution parameters derived from a multivariate discovery process model represent unbiased estimates of the parent population and allow a study on the correlation among the volumetric variables.

It is common that estimating the number of petroleum accumulations in a play is a difficult task due to the limitations of geological and geophysical data, as well as subjectivity in inferring the probability of petroleum occurrence. The Geo-anchored method can provide the estimates of the numbers of oil and gas accumulations as well as the oil and gas resources in a play with mixed oil and gas accumulation simultaneously without dividing pools in a natural group into different plays. A validation study in the application example shows that estimated numbers of oil and gas pools from the Geo-anchored method are consistent with both available geological and exploration data. The use of a discovery process model, like the Geo-anchored method, provides an alternative for the estimation of number of pools in cases where there is a lack of necessary alternative information for deriving such numbers. If the number of accumulations can be estimated from adequate geological and geophysical data, such a number derived from a discovery process model can serve as a cross check for ensuring the quality of assessment. It has been realized that the number of accumulations is a function of pool size. As shown in the application example, without specifying the associated pool size, the use of the number from an independent estimation in the calculation of play resource and individual accumulation sizes may lead to unrealistic results. The number of pools derived from the Geo-anchored method comes with a clear indication of its associated pool size range.

Petroleum resource assessment can be improved by crossvalidation of the results derived using different methods. Finding the causes of the differences in the assessment results and constraining the estimates by physical facts and geological understandings improve the reliability of the assessment.

\section{Acknowledgements}

Dr. J. Christopher Harrison, GSC is thanked for his critical comments and suggestions. Comments and suggestions from two anonymous journal reviewers improved the quality of the manuscript. This is ESS contribution \# 20080547.

\section{References}

Andreatta G and Kaufman G M. Estimation of finite population properties when sampling is without replacement and proportional to magnitude. Journal of the American Statistical Association. 1986. 81(395): 657-666 
Arps J J and Roberts T G. Economics of drilling for Cretaceous oil and gas on the east flank of the Denver-Julesberg Basin. AAPG Bulletin. 1958. 42(11): 2549-2566

Attanasi E D and Charpentier R R. A program for partitioning shifted truncated lognormal distributions into size-class bins. U. S. Geological Survey Open-File Report 2007-1260. 2007

Baker R A, Gehman H M, James W R, et al. Geologic field number and size assessments of oil and gas plays. AAPG Bulletin. 1984. 68(4): 426-431

Balkwill H R. Geology of Amund Ringnes, Cornwall and Haig-Thomas Islands, district of Franklin. Geological Survey of Canada, Memoir 390. 1983. 76p.

Balkwill H R and Roy K J. Geology, King Christian Island, district of Franklin. Geological Survey of Canada, Memoir 386. 1977. 28p.

Balkwill H R, Hopkins W S and Wall J H. Geology of Lougheed Island and nearby smaller islands, district of Franklin. Geological Survey of Canada, Memoir 395. 1982. 22p.

Barouch E, Chow S, Kaufman G M, et al. Properties of successive sample moment estimators. Studies in Applied Mathematics. 1985. 73(3): 239-260

Bickel P J, Nair V N and Wang P C C. Nonparametric inference under biased sampling from a finite population. Annals of Statistics. 1992. 20(2): $853-878$

Brekke H and Kalheim J E. The Norwegian Petroleum Directorate's assessment of the undiscovered resources of the Norwegian continental shelf-background and methods. In: Quantitative Prediction and Evaluation of Petroleum Resources (edited by Dore A G and Sinding-Larsen R). NPF Special Publication No.6. Elsevier. 1996. 91-104

Brooks P W, Embry A F, Goodarzi F, et al. Geochemical studies of Sverdrup Basin (Arctic Islands) - organic geochemistry and biological marker geochemistry of the Schei Point Group (Triassic) and recovered oils. Bulletin of Canadian Petroleum Geology. 1992. 40(3): 173-187

Cheng Y C, Lee P J and Lee T Y. Estimating exploration success ratio by fractal geometry. Bulletin of Canadian Petroleum Geology. 2000. 48(2): 116-122

Chen Z H. Quantification of Petroleum Resources through Sampling from a Parent Population and as a Function of Basin Yield. Trondheim, Norway: NTH Press. 1993. 230p.

Chen Z H and Sinding-Larsen R. Estimating petroleum resources using the Geo-anchored method - a sensitivity study. Natural Resources Research. 1999. 8(1): 49-58

Chen Z H and Osadetz K G. Geological risk mapping and prospect evaluation using multivariate and Bayesian statistical methods, western Sverdrup Basin of Canada. AAPG Bulletin. 2006. 90(6): 859-872

Chen Z H, Osadetz K G, Dixon J, et al. Impacts of variable interdependencies on petroleum play resource assessment and resource aggregation, example from Beaufort and Mackenzie Delta Basin, Canada. In: Geomathematics and GIS Analysis of Resources, Environment and Hazards, Proceedings of IAMG'07 (edited by Zhao P, Agterberg F and Cheng Q). Beijing, August 26-31. 2007. 615-619

Chen Z H, Osadetz K G, Embry A, et al. Geological favorability mapping of petroleum potential using fuzzy integration, example from western Sverdrup Basin, Canadian Arctic Archipelago. Bulletin of Canadian Petroleum Geology. 2002. 50(4): 492-506

Chen Z H, Osadetz K G, Gao H Y, et al. Characterizing the spatial distribution of the undiscovered hydrocarbon resource: the Keg River reef play, Western Canadian Sedimentary Basin. Bulletin of Canadian Petroleum Geology. 2000. 48(2): 150-161

Chen Z H, Sinding-Larsen R and Ma X H. Application of discovery process models in estimating petroleum resources at the play level in
China. Natural Resources Research. 1997. 6(4): 317-328

Chen Z H, Sinding-Larsen R and Sammatray R. The interdependencies between volumetric variables and their impact on petroleum resource assessment. In: Proceedings of the 94 Annual Meeting of International Association for Mathematical Geology. Quebec, Canada. Oct. 3-5, 1994. 68-73

Coustau H, Lee P J, Dupuy J, et al. The resources of the Eastern Sheltland Basin, North Sea: a comparison of evaluation methods. Bulletin of Canadian Petroleum Geology. 1988. 36(2): 177-185

Crovelli R A and Balay R H. FASP, an analytic resource appraisal program for petroleum play analysis. Computers and Geosciences. 1986. 12(4): $423-475$

Davis J C and Chang T. Estimating potential for small fields in mature petroleum province. AAPG Bulletin. 1989. 73(8): 967-976

Drew L J and Schuenemeyer J H. The evolution and use of discovery process models at the U.S. Geological Survey. AAPG Bulletin. 1993. 77(3): 467-478

Embry A F. Mesozoic history of the Arctic Islands. In: Geology of the Innuitian Orogen and Arctic Platform of Canada and Greenland (edited by Trettin H P). Geological Survey of Canada. 1991. 3: 369433

Embry A F, Powell T G and Mayr U. Resources, Arctic Archipelago, A Petroleum. In: Geology of the Innuitian Orogen and Arctic Platform of Canada and Greenland (edited by Trettin H P). Geological Survey of Canada. Geology of Canada No.3. 1991. 517-525

Forman D J and Hinde A L. Improved statistical method for assessment of undiscovered petroleum resources. AAPG Bulletin. 1985. 69(12): 873-893

Gehman H M, Baker R A and White D A. Assessment methodology, an industry viewpoint. In: Assessment of Undiscovered Oil and Gas. Bangkok, United Nations ESCAP, CCOP Technical Publication 10. 1980. 113-121

Grace J D. Advantages and limitations of discovery process modeling: the case of the northern west Siberian gas plays. In: Quantitative Analysis of Mineral and Energy Resources (edited by Chung C F, Fabbri A G and Sinding-Larsen R). D. Reidel Publishing Company. 1988. 651-668

Harrison J C. Melville Island's salt-based fold belt (Arctic Canada). Geological Survey of Canada. 1995. Bulletin 472

Kaufman G M. Finite population sampling methods for oil and gas resource estimation. In: Oil and Gas Assessment - Methods and Applications (edited by Rice D D). AAPG Studies in Geology \#21. 1986. 43-54

Kaufman G M. What has seismic missed? Natural Resources Research. 1994. 3(4): 304-314

Kaufman G M. Risk analysis: from prospect to exploration portfolio and back. In: Quantitative Prediction and Evaluation of Petroleum Resources (edited by Dore A G and Sinding-Larsen R). NPF Special Publication No.6. 1996. 135-152

Kaufman G M, Balcer Y and Kruyt D. A probabilistic model of oil and gas discovery. In: Estimating the volume of undiscovered oil and gas resources (edited by Haun J D). AAPG Studies in Geology Series No.1. 1975. 113-142

Kaufman G M, Crovelli R A, Chow S, et al. Oil and gas modeling and forecasting. In: Quantitative Analysis of Mineral and Energy Resources (edited by Chung C F, Fabbri A G and Sinding-Larsen R). D. Reidel Publication Company. 1988. 695-706

Lee P J. Oil and gas pool size probability distributions: J-shaped, lognormal, or Pareto? GSC Current Research. 1993. 93

Lee P J. Analyzing multivariate oil and gas discovery data. In: Proceedings of the 4th Annual Conference of the International Association of Mathematical Geology (edited by Buccianti A, Nardi G and Polenza R). Island of Ichia, Italy. 1998. 1: 445-451

Lee P J. Statistical Methods for Estimating Petroleum Resources. 
Oxford: Oxford University Press. 2008. 234p.

Lee P J and Gill D. Comparison of discovery process methods for estimating undiscovered resources. Bulletin of Canadian Petroleum Geology. 1999. 47(1): 19-30

Lee P J and Wang P C C. Probabilistic formulation of a method for the evaluation of petroleum resources. Mathematical Geology. 1983. 15(1): 163-181

Lee P J and Wang P C C. Prediction of oil or gas pool sizes when discovery record is available. Mathematical Geology. 1985. 17(2): 95-113

Lee P J, Osadetz K and Hannigan P. Estimating oil and gas pool-size distributions - examples from the Western Canada Sedimentary Basin. In: Proceedings of the 5th Annual Conference of the International Association of Mathematical Geology (edited by Lippard S J, Neass A and Sinding-Larsen R). Trondheim, Norway. 6-11th August, 1999. 439-444

Lee P J, Snowdon L R and Wang P C C. Petroleum resource evaluation, short course notes. C.S.P.G. Convention. Calgary, Canada. 1990

Logan K G. The truncated discovery process model. Natural Resources Research. 2005. 14(3): 265-281

Meneley R A, Calverley A E, Logan K G, et al. Resource assessment methodologies: current status and future direction. AAPG Bulletin. 2003. 87(4): 535-540

Schmoker J W and Klett T R. U. S. Geological Survey assessment model for undiscovered conventional oil, gas, and NGL resourcesthe seventh approximation. In: U. S. Geological Survey World Petroleum Assessment 2000-Description and Results (edited by U. S. Geological Survey World Energy Assessment Team). U. S. Geological Survey Digital Data Series DDS-60. 2000. 1-18

Schuenemeyer J H and Drew L J. A procedure to estimate the parent population of the size of oil and gas fields as revealed by a study of economic truncation. Mathematical Geology. 1983. 15(1): 145-161

Sinding-Larsen R and Chen Z H. Cross validation of resource estimations from discovery process modeling and volumetric accumulation modeling at play level: example from the lower and middle Jurassic play of Halten Terrace, Offshore Norway. In: Quantitative Prediction and Evaluation of Petroleum Resources (edited by Dore A G and Sinding-Larsen R). NPF Special Publication No.6. 1996. 105-114

Sinding-Larsen $\mathrm{R}$ and $\mathrm{Xu} \mathrm{J} \mathrm{Z}$. Bayesian discovery process modeling of the lower and middle Jurassic play of the Halten Terrace, offshore Norway, as compared with the previous modeling. Natural Resources Research. 2005. 14(3): 235-248

Wang P C C and Nair V N. Statistical analysis of oil and gas discovery data. In: Quantitative Analysis of Mineral and Energy Resources (edited by Chung C F, Fabbri A G and Sinding-Larsen R). D. Reidel Publication Company. 1988. 199-214

Waylett D C and Embry A F. Hydrocarbon loss from oil and gas fields of the Sverdrup Basin, Canadian Arctic Island. In: Arctic Geology and Petroleum Potential (edited by Vorren T O, Bergsager E, DahlStamnes O A, et al). NPF Special Publication No.2. 1993. 195-204

White D A, Garrett Jr R W, Marsh G R, et al. Assessing regional oil and gas potential. In: Methods of Estimating Oil and Gas Resources (edited by Haun J D). AAPG Studies in Geology Series \#1. 1975. 143-159

\section{Appendix}

\section{The Geo-anchored method}

The Geo-anchored method (Chen, 1993; Chen and Sinding-Larsen, 1999) is a discovery process model based on a successive sampling model of finite population (Andreatta and Kaufman, 1986; Barouch et al, 1985), which can be written in the following forms (Chen and Sinding-Larsen, 1999):

$$
\hat{R}=\sum_{i=1}^{n} y_{i} / \pi_{i}(n)
$$

and

$$
\hat{N}=\sum_{i=1}^{n} 1 / \pi_{i}(n)
$$

where $y_{i}$ is the magnitude of the $i^{\text {th }}$ discovery, $i=1,2, \cdots, n, \hat{R}$ is the estimated expectation of the play potential and $\hat{N}$ is the estimated expectation of the number of deposits in the finite population. $\pi_{i}(n)$ is the inclusion probability (Kaufman, 1986), which can be approximated by the following relation (Chen, 1993; Chen and Sinding-Larsen, 1999):

$$
\pi_{i}(n)=\left(1-\exp \left\{-y_{i} \sum_{k=1}^{n} \frac{1}{\hat{R}-\sum_{l=0}^{k-1} y_{l}}\right) \quad y_{0}=0\right.
$$

In the case of a play with associated oil and gas, the magnitude represents the summation of oil and gas volumes. The play potential of oil and gas resources and the number of accumulations can then be estimated separately using the same equation pairs (Eqs. (A-1) and (A-2)) with a minor modification. For more detailed discussion on the Geoanchored method, the reader is referred to Chen (1993), and Chen and Sinding-Larsen (1999).

\section{Multivariate Discovery Process model (MDP)}

A basic assumption in a discovery process model is that the probability of discovering a petroleum accumulation is proportional to its magnitude. The magnitude can be expressed in various formats, such as pool size, petroleum pore volume, pool area or even a function of geological variables. Wang and Nair (1988) proposed a general form of magnitude to deal with the problem that different variables may have different impacts on the order of discoveries:

$$
w_{i}^{\beta}=v_{i 1}^{\beta_{1}} v_{i 2}^{\beta_{2}}, \cdots, v_{i m}^{\beta_{m}}
$$

where $w_{i}$ is the magnitude of the $i^{\text {th }}$ discovery, $v_{i 1}, v_{i 2}, \cdots, v_{i m}$ are the variables that have impact on the order of discovery and $\beta_{1}, \beta_{2}, \cdots, \beta_{m}$ are the exponents measuring the degree of influences.

When the magnitude of the accumulation is a function of multiple variables, such as expressed in the reservoir volumetric equation (Eq. (1) or Eq. (2)), a univariate discovery process model, like the log-normal discovery process model (LDP) of the GSC (Lee and Wang, 1985) becomes a multivariate discovery process model (MDP), which can be written in terms of a joint density function (Lee, 1998; 2008):

$$
\frac{N !}{(N-n) !} \prod_{j=1}^{n} f_{\theta}\left(z_{j}\right) E_{\theta}\left[\prod_{j=1}^{n} \frac{z_{j}}{b_{j}+z_{n+1}+\ldots+z_{N}}\right]
$$


where $b_{j}=z_{j}+\cdots+z_{n}$ denote the discovered pools, $z_{n+1}, \cdots, z_{N}$ denote the undiscovered pools, $\theta$ represents the population parameter set for the multivariate distribution, and $N ! /(N-n)$ ! is the number of order samples of size $n$ without replacement from a population of $N$ pools or fields. $f_{\theta}\left(z_{j}\right)$ is the probability density function and can take any form. In this study, we use the log-normal function to approximate the pool size distribution. More generally, each volumetric variable in Eq. (2) may have an assigned exponent to express its impact on the order of discovery. Details regarding the MDP model can be found in Lee (1999).

(Edited by Hao Jie) 